\title{
Definition of CD4 immunosignatures associated with MTB
}

\section{Cecilia S. Lindestam Arlehamn* and Alessandro Sette}

Division of Vaccine Discovery, La Jolla Institute for Allergy and Immunology, La Jolla, CA, USA

\section{Edited by:}

Tom H. M. Ottenhoff, Leiden University Medical Center,

Netherlands

\section{Reviewed by:}

Dirk Dittmer, University of North

Carolina at Chapel Hill, USA

Heinrich Korner, Menzies Research

Institute Tasmania, Australia

*Correspondence:

Cecilia S. Lindestam Arlehamn, Division of Vaccine Discovery, La Jolla Institute for Allergy and Immunology, 9420 Athena Circle, La Jolla, CA 92037, USA

e-mail: cecilia@liai.org
We have recently described the first true genome-wide screen for $\mathrm{CD} 4^{+}$T-cell reactivity directed against Mycobacterium tuberculosis (MTB) in latent TB-infected individuals. The approach relied on predictions of HLA-binding capacity for a panel of DR, DP, and DQ alleles representative of those most commonly expressed in the general population, coupled with high throughput ELISPOT assays. The results identified hundreds of novel epitopes and antigens, and documented the novel observation that T cells in latent MTB infection are confined to the $\mathrm{CXCR}^{+}{ }^{+} \mathrm{CR} 6^{+}$phenotype and largely directed against three antigenic "islands" within the MTB genome. In parallel, we have made generally available to the scientific community the technical approaches and reagents developed in the process, such as motifs, algorithms, and binding assays for several common HLA class II alleles, and a panel of single allele HLA class II transfected cell lines representative of the most frequent specificities in the general population. Recent efforts have been focused on characterization of epitopes and antigens recognized by patients with active TB and individuals vaccinated with $B C G$, with the aim of providing the first systematic evaluation of the overlap between latent, active, and BCG cohorts. The definition of a broad range of epitopes restricted by common HLA molecules, will facilitate development of diagnostic reagents, allow a rigorous evaluation of T-cell responses associated with TB infection in humans, and enable the evaluation of the immunogenicity of different vaccine candidates. Furthermore, it might suggest new candidates for vaccine and diagnostic development.

Keywords: tuberculosis, T cells, epitope, HLA, genome-wide

\section{TB AS A WORLDWIDE MEDICAL PROBLEM}

Tuberculosis is the second leading cause of death from infectious diseases worldwide (1). The World Health Organization (WHO) estimates that approximately one-third of the world's population (two billion total) is infected with Mycobacterium tuberculosis (MTB). MTB is responsible for 1.4 million deaths annually and 9 million new infections are reported each year. The majority of infected individuals control the pathogen by mounting a successful, long-lived, and protective immune response, leading to either resolution or a clinically latent infection. Approximately, $10 \%$ of latently infected individuals subsequently develop active TB $(2,3)$. The risk of developing active tuberculosis is higher in immunocompromised individuals (due to age, corticosteroids, malnutrition, HIV infection, etc.). Treatment is lengthy and expensive, requiring a combination of antibiotics. In many parts of the world, access to these drugs is limited and compliance with the drug regime is often poor, thus precipitating the development of drug-resistant strains. Worldwide, $3.7 \%$ of new cases and $20 \%$ of previously treated cases are infected with multidrug-resistant $\mathrm{TB}$ (MDR-TB), extensively drug-resistant TB (XDR-TB) and recently virtually untreatable totally drug-resistant (TDR) strains $(1,4)$. The prevalence of these drug-resistant cases, which complicates the schedule and increases cost of treatment, has heightened interest in the development of effective vaccines, and prompted inclusion of MTB in the list of A-C pathogens. The vaccination of children with Mycobacterium bovis BCG results in a $60-80 \%$ decrease in the incidence of active tuberculosis. However, in most developed countries BCG vaccination is not recommended due to the relatively low incidence of disease and variable effectiveness in preventing pulmonary TB in adults, a large fraction of active disease cases.

\section{CD4 T-CELL RESPONSES IN TB INFECTION}

Due to the intracellular lifestyle of MTB, immunity relies on a successful T-cell response against a repertoire of antigenic targets. Defining this is central to understanding the immune response against TB and it has been vigorously pursued. Human T-cell responses to MTB involve $\mathrm{CD} 4, \mathrm{CD} 8, \mathrm{CD} 1$, and $\gamma \delta \mathrm{T}$ cells, though protective immunity to MTB is commonly ascribed to a Th1 profile $(3,5-8) . C D 4^{+}$T cells are central to the defense against MTB, as exemplified by the fact that HIV-infected patients are more susceptible to primary TB infection, reinfection, and reactivation (9-11). Seminal studies in human T-cell responses to MTB showed that memory Th1 cells secreted IFN $\gamma$ (12). It was further shown that IFN $\gamma$ has an essential role in the protective immunity to mycobacteria, as individuals with genetic defects in the IFN $\gamma$ receptor have an increased susceptibility to infection with mycobacteria (13). Furthermore, TNF $\alpha$ is important in host resistance to TB, as evidenced by studies following anti-TNF $\alpha$ therapy for autoimmune disease, where patients with LTBI have been observed to develop active TB $(14,15)$. Other Th subsets and cytokines have been shown to be involved in the T-cell response to MTB. Several studies indicate that lower IFN $\gamma / \mathrm{IL}-4$ or IFN $\gamma / \mathrm{IL}-5$ ratios are found in active TB patients compared to healthy TB controls (16, 
17). Furthermore, healthcare workers that have worked in close proximity to TB patients, and subsequently developed TB, showed increased IL-5 levels compared to healthcare workers that did not develop TB (18). Definition of the exact role of Th2 responses still requires more investigation. Furthermore, several studies suggest that the capacity to secrete multiple cytokines can determine pathogen clearance versus persistence (19). Indeed, several studies in TB have suggested that multifunctional $\mathrm{T}$ cells are not only a potential correlate of protection, but have also been implicated in pathology (20-23). Recently, MTB-specific T-cell expression of IL-17 has been described (24-27). It has been demonstrated that the BCG vaccine and purified protein derivative (PPD) are able to expand memory CD4 ${ }^{+} \mathrm{IL}-17^{+}$cells $(24,26)$. Furthermore, $\mathrm{IL}-17^{+}$ $\mathrm{T}$ cells have been described in active TB patients, particularly in those infected by MDR MTB strains $(27,28)$, suggesting a pathogenic role for this cytokine. There is also evidence for IL-10 as a factor in humans with active TB, where IL-10 mediates inhibition of antigen presentation to $\mathrm{T}$ cells, and therefore mediates a decreased ability to clear infection contributing to TB pathogenesis (29). IL-10 has been shown to be elevated in serum from active pulmonary TB patients (30). Therefore, the involvement of different Th subsets in TB infection remains to be clarified and definition of human $\mathrm{CD} 4^{+}$T-cell epitopes to specifically track pathogen-specific T-cell subsets remains a high priority.

\section{THE CONCEPT OF HLA PROMISCUITY}

$\mathrm{T}$ cells recognize specific complexes formed between $\mathrm{MHC}$ molecules and particular peptide epitopes. Accordingly, a given epitope will elicit a T-cell response only in individuals expressing MHC molecules having the capacity to bind it with sufficiently high affinity. Both class I and class II MHC molecules are extremely polymorphic, and thousands of different variants are known in humans $(31,32)$. The most frequent HLA class II alleles with population coverage of almost $90 \%$ at each locus are shown in Table 1. Much of the polymorphism is concentrated on residues located in the peptide-binding groove, giving each allelic variant a distinct binding specificity. As a result, the prediction, identification, and validation of epitopes restricted by each HLA type represent tasks of such complexity as to be practically unfeasible. Further, different MHC types are expressed at dramatically different frequencies in and across different ethnicities. Thus, without careful consideration, ethnically unbiased population coverage is difficult to obtain.

One mean of circumventing the problem is to focus on the HLA types that are most widely represented in different ethnicities worldwide (Table 1), while at the same time selecting epitopes that are capable of binding multiple common HLA types (promiscuous epitopes). In this respect, it has been found that both class I and II HLA molecules can be classified into groups, denominated as supertypes that reflect shared or largely overlapping peptide-binding repertoires and specificities. Indeed, a large body of evidence demonstrates that the repertoire of peptides bound by different HLA class II molecules significantly overlap (32), and peptides with promiscuous binding capacity are also quite common [see, e.g., $(34,35)]$. Overlaps in the repertoires of DRB1 and DRB3/4/5 molecules, leading to the definition of a DR supertype, as well as the identity of well-characterized CD4 T-cell epitopes
Table 1 | Genotype and phenotype frequencies of HLA class II alleles.

\begin{tabular}{|c|c|c|c|}
\hline Locus & Allele & $\begin{array}{l}\text { Genotype } \\
\text { frequency }\end{array}$ & $\begin{array}{l}\text { Phenotype } \\
\text { frequency }\end{array}$ \\
\hline \multirow[t]{26}{*}{ DRB1 } & DRB1*01:01 & 2.8 & 5.4 \\
\hline & DRB1*03:01 & 7.1 & 13.7 \\
\hline & DRB1*03:02 & 1.1 & 2.1 \\
\hline & DRB1*04:01 & 2.3 & 4.6 \\
\hline & DRB1*04:02 & 1.1 & 2.2 \\
\hline & DRB $1 * 04: 03$ & 2.3 & 4.5 \\
\hline & DRB $1 * 04: 04$ & 1.9 & 3.8 \\
\hline & DRB1*04:05 & 3.1 & 6.2 \\
\hline & DRB1*04:07 & 2.4 & 4.8 \\
\hline & DRB $1{ }^{*} 04: 11$ & 1.6 & 3.3 \\
\hline & DRB1*07:01 & 7 & 13.5 \\
\hline & DRB1*08:02 & 2.5 & 4.9 \\
\hline & DRB1*09:01 & 3.1 & 6.2 \\
\hline & DRB1*11:01 & 6.1 & 11.8 \\
\hline & DRB1*11:02 & 1.1 & 2.2 \\
\hline & DRB1*11:03 & 0.3 & 0.5 \\
\hline & DRB1*11:04 & 1.4 & 2.8 \\
\hline & DRB1*12:01 & 2 & 3.9 \\
\hline & DRB1*13:01 & 3.2 & 6.3 \\
\hline & DRB1*13:02 & 3.9 & 7.7 \\
\hline & DRB1*13:03 & 1.2 & 2.4 \\
\hline & DRB1*13:04 & 0.1 & 0.2 \\
\hline & DRB1*14:01 & 3.4 & 6.7 \\
\hline & DRB1*14:02 & 2.8 & 5.6 \\
\hline & DRB1*15:01 & 6.3 & 12.2 \\
\hline & DRB1*16:01 & 1 & 1.9 \\
\hline DRB1 & Total & 71.1 & 91.7 \\
\hline \multirow[t]{6}{*}{ DRB3/4/5 } & DRB3*01:01 & 14 & 26.1 \\
\hline & DRB3*02:02 & 18.9 & 34.3 \\
\hline & DRB3*03:01 & 6.7 & 13 \\
\hline & DRB4* 01:01 & 23.7 & 41.8 \\
\hline & DRB5*01:01 & 8.3 & 16 \\
\hline & DRB5*01:02 & 5.1 & 9.8 \\
\hline DRB3/4/5 & Total & 76.7 & 94.6 \\
\hline \multirow[t]{8}{*}{ DQA1/DQB1 } & DQA1*05:01/DQB1*02:01 & 5.8 & 11.3 \\
\hline & $\mathrm{DQA} 1 * 02: 01 / \mathrm{DQB} 1 * 02: 01$ & 5.7 & 11.1 \\
\hline & DQA1*05:01/DQB1*03:01 & 19.5 & 35.1 \\
\hline & DQA1*03:01/DQB1*03:02 & 10 & 19 \\
\hline & DQA1*04:01/DQB1*04:02 & 6.6 & 12.8 \\
\hline & DQA1*01:01/DQB1*05:01 & 7.6 & 14.6 \\
\hline & DQA $1 * 01: 02 / D Q B 1 * 05: 02$ & 3.5 & 6.9 \\
\hline & DQA1*01:02/DQB1*06:02 & 7.6 & 14.6 \\
\hline DQA1/DQB1 & Total & 66.3 & 88.7 \\
\hline \multirow[t]{6}{*}{ DPA1/DPB1 } & DPA1*02:01/DPB1*01:01 & 8.4 & 16 \\
\hline & DPA1*01:03/DPB1*02:01 & 9.2 & 17.5 \\
\hline & DPA1*01:03/DPB1*04:01 & 20.1 & 36.2 \\
\hline & DPA1*01:03/DPB1*04:02 & 23.6 & 41.6 \\
\hline & DPA1*02:02/DPB1*05:01 & 11.5 & 21.7 \\
\hline & DPA1*02:01/DPB1* 14:01 & 3.8 & 7.4 \\
\hline DPA1/DPB1 & Total & 76.5 & 94.5 \\
\hline
\end{tabular}

Average genotype and phenotype frequencies for individual alleles are based on data available at dbMHC, as previously described by McKinney et al. (33). Alleles previously characterized in detail for binding specificity are highlighted in bold (32). 
with promiscuous DR-binding capacity, have been known for over a decade (34-36). Other studies have similarly addressed repertoire overlaps and the existence of corresponding supertypes for DP (32, 37-39) and DQ (32, 40, 41).

Following upon earlier computational, structural, and functional approaches to define class II supertypes (42-45), we utilized a large library of HLA DR-, DQ-, and DP-binding data to define seven different class II supertypes (main DR, DR4, DRB3, main DQ, DQ7, main DP, and DP2) (32). The molecules associated with the respective supertypes fell largely along lines defined by MHC locus and reflect, in broad terms, commonalities in reported peptide-binding motifs. Repertoire overlaps between molecules within the same class II supertype were found to be similar in magnitude to what has been observed for HLA class I supertypes. Surprisingly, however, the degree to which repertoires between molecules in the different class II supertypes overlapped was found to be fivefold to tenfold higher than repertoire overlaps typically noted between molecules in different class I supertypes. These results highlight the existence of a high degree of repertoire overlap amongst all HLA class II molecules, regardless of supertype association. Further, in terms of implications for epitope identification studies, these data also validate the idea that broadly reactive HLA class II epitopes can be defined.

\section{HLA PROMISCUITY IMPLICATIONS FOR EPITOPE IDENTIFICATION}

Peptides with highly promiscuous binding capacity are frequently recognized by immune individuals (34, 46-49) and epitope immunodominance is highly influenced by promiscuous recognition in the context of multiple HLA class II molecules (50). Furthermore, a dominant fraction of the pathogen or allergen-specific response can be identified by selection of the most promiscuous binding peptides using bioinformatic predictions (51-54). The advantage of this approach is that it would identify the optimal set of peptide candidates for immunogenicity testing, eliminating the necessity of synthesizing a large number of overlapping peptides and, more importantly, circumvent the need to test each one of them for binding to numerous HLA class II molecules in vitro.

We have recently described the selection of a panel of HLA DR, DQ, and DP specificities that provide worldwide population (phenotypic) coverage of almost $90 \%$ at each locus, and accounts for over $66 \%$ of all genes at each locus (32) (Table 1). Considering up to eight different class II alleles expressed per individual (i.e., up to two at each of the four class II loci - DRB1, DRB3/4/5, DQ, and DP), this panel afforded coverage of at least four alleles in over $95 \%$ of the individuals in four different study populations of diverse ethnicity from the USA and South Africa (33). For each of these allelic variants, single HLA class II allele-transfected cell lines have been generated (33). These transfected cell lines can be used for high throughput determination of HLA restriction, enabling better characterization of T-cell responses, and facilitating the development of tetrameric staining reagents. Also, for the vast majority of these alleles high throughput binding assays have been established, peptide-binding motifs defined, and predictive algorithms developed and made publically available $(32,55)$, enabling efficient and thorough identification of candidate epitopes, as well as characterization of their HLA-binding capacity and potential population coverage.
Taken together, these data highlight that broadly reactive HLA class II epitopes can be identified, and that these promiscuous epitopes can account for a large fraction of the specific immune response. Further, the bioinformatic tools necessary to identify candidate epitopes, as well as specific cellular and immunochemical reagents to allow detailed characterization of epitope-specific responses are available and have been well-validated in several studies.

\section{SCREEN OF A GENOME-WIDE LIBRARY OF MTB-DERIVED PREDICTED HLA CLASS II EPITOPES IN LTBI DONORS}

The MTB genome encodes more than 4,000 different open reading frames (ORFs) (56), generally highly conserved amongst different strains, including drug-resistant ones. Identification of T-cell epitopes from such a large and complex target is a complex task, yet necessary for disease monitoring, vaccine evaluations, and development. A comprehensive genome-wide screen for HLA class II epitopes was recently performed (57). This genome-wide screen analyzed the reactivity of latent TB-infected (LTBI) individuals from the San Diego area. LTBIs were initially chosen as representative of a patient population that is, at least in part, capable of containing TB infection. Several 100 novel CD4-restricted epitopes and many antigens were identified (57). Furthermore, this study documented the novel observation that $\mathrm{T}$ cells in latent MTB infection are confined to the recently described $\mathrm{CXCR} 3^{+} \mathrm{CCR} 6^{+}$phenotype $(24,58)$ and largely directed against three antigenic "islands" within the MTB genome. Still, important gaps in epitope knowledge remain, as also highlighted in the TB research community, in particular after the disappointing results of the MVA85A BCG boost human vaccine trial (59).

To enable a genome-wide screen for epitopes recognized by LTBIs (57), protein sequences from five complete (CDC1551, F11, H37Ra, H37Rv, and KZN 1435) MTB genomes and 16 draft assemblies available in the NCBI Protein database were aligned. To select candidate promiscuous epitopes, the binding capacity of all possible 15-mer peptides was predicted for 22 HLA DR, DP, and DQ class II alleles commonly expressed in the general population and for which validated algorithms were available $(32,52)$. This approach eliminates the need to test each peptide in vitro for HLA class II binding, as well as the necessity of synthesizing overlapping peptides. The resulting synthetic peptide library of $20,610$ peptides (2-10 per ORF, average 5$)$, were tested in high throughput ex vivo IFN $\gamma$ ELISPOT using circulating $\mathrm{T}$ cells from LTBI donors. Each individual donor tested recognized 24 epitopes on average, revealing striking heterogeneity of responses to MTB. The epitopes identified were ranked on the basis of magnitude of response to assess their relative dominance. Overall, the top 80 epitopes accounted for $75 \%$ of the total response and the top 175 epitopes accounted for $90 \%$ of the total response. The epitopes were mapped to individual MTB antigens using the H37Rv as a reference genome. A total of 82 antigens were recognized by more than $10 \%$ of LTBI donors, accounting for approximately $80 \%$ of the total response. Thus, natural immunity to MTB is multiantigenic. Taken together, these results demonstrate the feasibility, novelty, and success of the genome-wide screen for epitopes recognized by LTBIs. 


\section{CHARACTERISTICS OF HLA CLASS II RESTRICTED ANTIGENS IDENTIFIED BY THE GENOME-WIDE APPROACH}

The protein category and the genomic location of the identified antigens were determined using the TubercuList database (60). This revealed enrichment for responses against cell wall-associated and secreted proteins, however, strong immune responses were induced by both secreted and non-secreted proteins, consistent with earlier antigen discovery efforts (61-63). The localization of antigens recognized by the LTBI donors was visualized by plotting the recognition data on a linear map of the MTB genome. This revealed striking clusters of reactivity within certain regions of the genome. In particular, three significant antigenic islands, which encode $0.55 \%$ of the total ORFs, accounted for $42 \%$ of the total response. All three islands were shown to contain ESX protein pairs, such as the well-known Rv3875 (Early Secretory Target-6, ESAT-6) and Rv3874 (Culture Filtrate Protein 10, CFP10) (64), and two also contain Type VII secretion systems ESX-1 and ESX-3.

\section{METHODS TO CHARACTERIZE AND VALIDATE IDENTIFIED EPITOPES}

Characterization and tracking of pathogen-specific T cells can be achieved once specific T-cell epitopes have been defined. Here, we briefly review our published data relating to the characterization of T cells derived from LTBI donors (57). A variety of approaches were employed in parallel including multiparameter intracellular cytokine staining (ICS) assays, tetramer staining, and T-cell libraries (65). It was found that $\mathrm{CD} 4^{+} \mathrm{T}$ cells recognizing epitopes derived from different TB antigens were associated with similar multifunctional cytokine expression patterns. The most frequent $\mathrm{CD}^{+}{ }^{+} \mathrm{T}$ cells were IFN $\gamma^{+} \mathrm{TNF} \alpha^{+} \mathrm{IL}_{-} 2^{+}$or IFN $\gamma^{+} \mathrm{TNF}^{+}$, followed by $\mathrm{TNF}^{+}$single producing $\mathrm{CD}^{+}{ }^{+} \mathrm{T}$ cells. To a lesser extent, $\mathrm{TNF}^{+} \mathrm{IL}^{-} 2^{+}$, single IFN $\gamma^{+}$, and single IL-2 ${ }^{+}$cells were also detected.

To characterize the responding $\mathrm{T}$ cells in depth, HLA-epitope tetramer reagents were prepared for representative epitopes for staining of $\mathrm{CD}^{+}$purified cells. To overcome low T-cell frequency, a magnetic bead enrichment technique was preformed $(50,66)$. This allowed phenotypic characterization of epitopespecific memory subsets (57) as well as Th subset characterization (manuscript in preparation).

An alternative and complementary approach to ICS and tetrameric staining reagents is the screening of T-cell libraries (65). This high throughput method allows determination of frequency and distribution of pathogen/antigen/epitope-specific T cells (67).

\section{THE REPERTOIRE OF T-CELL EPITOPES IN THE DIFFERENT} CLINICAL MANIFESTATIONS OF MTB IS NOT FULLY DEFINED

The work described above developed reagents and approaches to broadly characterize human T-cell epitopes in the general human population $(32,33,39,41,68)$, and characterized in detail the T-cell epitopes recognized in a panel of model TB antigens (50). Most importantly, using LTBI donor PBMCs, we performed the first truly genome-wide screen of ex vivo human $\mathrm{CD}^{+} \mathrm{MTB} \mathrm{T}$ cell reactivity. Since latently infected individuals are able to control infection, they provided a logical relevant "first step" population to study protective responses. Mapping T-cell responses from these individuals identified immunodominant $\mathrm{CD} 4^{+}$T-cell antigens associated with potentially protective responses, and thus relevant to vaccine design.

According to most classifications, three primary and different outcomes can follow MTB exposure. The first, active TB infection is usually associated with evidence of bacterial replication. The second, LTBI, is usually associated with no disease symptoms and an effective immune response. And thirdly, reactivation of tuberculosis is often triggered by immunosuppression (69). MTB is believed to express different proteins in different stages of infection that may give rise to stage-specific immune responses and recognition of different antigens. Evidence of infection and stagespecific antigens in humans has indeed been reported $(70,71)$. In granulomas, MTB is believed to be in a dormant state, triggered by a range of stress factors including hypoxia, low $\mathrm{pH}, \mathrm{NO}$, nutrient deprivation, and host immune pressure (72). Under these conditions, genes encoded by the DosR regulon are upregulated $(73,74)$ and several antigens encoded by this regulon have been described as preferentially recognized by individuals with LTBI $(71,75-77)$. In addition, some proteins have been described and referred to as "resuscitation antigens" $(78,79)$. These are small bacterial proteins that promote proliferation of dormant mycobacteria, and are therefore believed to be involved in the reactivation of MTB (80). However, these antigens have not been described as being preferentially associated with a certain stage of infection. The availability of prediction methods and high throughput assays makes it possible to investigate genome-wide disease stage-specific TB reactivity and they can be applied to other pathogen systems.

\section{VACCINATION AGAINST TB: NEED FOR REAPPRAISAL OF BCG}

One of the long-term strategies essential for control of the global TB epidemic is effective vaccination. The only available licensed $\mathrm{TB}$ vaccine to date, $\mathrm{BCG}$, protects against disseminated tuberculosis in young children but offers very variable protection against pulmonary tuberculosis (the contagious transmittable form of the disease) in children and adults (81-83).

Several candidate TB vaccines are in clinical trial and many of them are designed to boost the BCG response. One candidate is MVA85A (modified Vaccinia Ankara virus expressing antigen 85A; Rv3804c), which was developed as a heterologous boost for BCG $(84,85)$. Rv3804c is highly conserved amongst mycobacterial species and it is present in all strains of BCG (86). MVA85A was shown to boost pre-existing antimycobacterial immune responses induced by either environmental mycobacteria or BCG vaccination (84). A recent phase $2 \mathrm{~b}$ study demonstrated the feasibility of a large efficacy trial of a new TB vaccine in a high-burden setting (59). This landmark trial was the first infant efficacy trial in over 50 years and its protocols and design will provide a reference for future trials and vaccination strategies. Unfortunately, however, the trial failed to show any efficacy against MTB infection in infants. Various hypotheses have been proposed to explain the lack of efficacy. Amongst them is the hypothesis that boosting with an antigen conserved in all mycobacterial species does not provide any additional benefit over the immunity already induced by exposure to environmental mycobacteria or BCG.

BCG was developed 90 years ago, but there is still a fundamental need for more knowledge regarding the actual mechanism 
of BCG immunogenicity, immunodominance, and crossreactivity with TB. Several studies have investigated mycobacterial antigenspecific human T-cell responses primed by vaccination with BCG (62, 87, 88). However, a genome-wide screen for epitopes has not previously been performed and would provide important immunological answers. First, it is imperative to clearly define the TB antigens that are primed following BCG vaccination. Identification of the antigens that are dominantly recognized following BCG vaccination and also recognized in natural TB infection would be important information for the design of BCG primeboosting vaccines. Conversely, identification of antigens that are primed by BCG but are either weakly or not recognized in natural TB infection could provide new vaccination strategies, as elimination of such antigens may improve BCG efficacy. Second, the characterization of the T-cell phenotypes associated with recognition of various antigens in the context of BCG vaccination and natural infection may provide clues to the type of immune response that might be most desirable, and additionally indicate how the vaccine response should be modulated (i.e., by use of specific adjuvants). Finally, the identification and characterization of epitopes and antigens recognized following BCG vaccination would provide important tools to monitor and evaluate different vaccine candidates, or different vaccination strategies examining dose, route, and the use of different adjuvants. In conclusion, as it is likely that a large proportion of future vaccine recipients will be BCG immunized at birth, and because several new vaccine candidates aim at either replacing or augmenting the efficacy of the BCG vaccine (89-91), a thorough understanding of the immune response following BCG vaccination and in different disease stages of TB infection will provide much needed information toward future TB vaccine design and more efficacious predictive diagnostic tests.

\section{ACKNOWLEDGMENTS}

This work was supported by National Institutes of Health contract N01-A1-900044C.

\section{REFERENCES}

1. WHO. Global Tuberculosis Report 2012. Geneva: World Health Organization (2012).

2. Comstock GW. Epidemiology of tuberculosis. Am Rev Respir Dis (1982) 125:8-15.

3. Kaufmann SH. Is the development of a new tuberculosis vaccine possible? Nat Med (2000) 6:955-60. doi:10.1038/79631

4. Velayati AA, Masjedi MR, Farnia P, Tabarsi P, Ghanavi J, Ziazarifi AH, et al. Emergence of new forms of totally drug-resistant tuberculosis bacilli: super extensively drug-resistant tuberculosis or totally drug-resistant strains in Iran. Chest (2009) 136:420-5. doi:10.1378/chest.08-2427

5. Boom WH. The role of T-cell subsets in Mycobacterium tuberculosis infection. Infect Agents Dis (1996) 5:73-81.

6. Flynn JL, Chan J. Immunology of tuberculosis. Annu Rev Immunol (2001) 19:93-129. doi:10.1146/annurev.immunol.19.1.93

7. Kaufmann SHE. How can immunology contribute to the control of tuberculosis? Nat Rev Immunol (2001) 1:20-30. doi:10.1038/35095558

8. Jung Y-J, Ryan L, Lacourse R, North RJ. Properties and protective value of the secondary versus primary $\mathrm{T}$ helper type 1 response to airborne Mycobacterium tuberculosis infection in mice. J Exp Med (2005) 201:1915-24. doi:10.1084/jem. 20050265

9. Barnes PF, Bloch AB, Davidson PT, Snider DE Jr. Tuberculosis in patients with human immunodeficiency virus infection. N Engl J Med (1991) 324:1644-50. doi:10.1056/NEJM199106063242307
10. Hopewell PC. Impact of human immunodeficiency virus infection on the epidemiology, clinical features, management, and control of tuberculosis. Clin Infect Dis (1992) 15:540-7. doi:10.1093/clind/15.3.540

11. Raviglione MC, Snider DE Jr, Kochi A. Global epidemiology of tuberculosis. Morbidity and mortality of a worldwide epidemic. JAMA (1995) 273:220-6. doi:10.1001/jama.1995.03520270054031

12. Del Prete GF, De Carli M, Mastromauro C, Biagiotti R, Macchia D, Falagiani P, et al. Purified protein derivative of Mycobacterium tuberculosis and excretorysecretory antigen(s) of Toxocara canis expand in vitro human $\mathrm{T}$ cells with stable and opposite (type $1 \mathrm{~T}$ helper or type $2 \mathrm{~T}$ helper) profile of cytokine production. J Clin Invest (1991) 88:346-50. doi:10.1172/JCI115300

13. Newport MJ, Huxley CM, Huston S, Hawrylowicz CM, Oostra BA, Williamson $\mathrm{R}$, et al. A Mutation in the interferon- $\gamma$-receptor gene and susceptibility to mycobacterial infection. N Engl J Med (1996) 335:1941-9. doi:10.1056/ NEJM199612263352602

14. Keane J, Gershon S, Wise RP, Mirabile-Levens E, Kasznica J, Schwieterman $\mathrm{WD}$, et al. Tuberculosis associated with infliximab, a tumor necrosis factor $\alpha$-neutralizing agent. N Engl J Med (2001) 345:1098-104. doi:10.1056/ NEJMoa011110

15. Galloway JB, Hyrich KL, Mercer LK, Dixon WG, Fu B, Ustianowski AP, et al. Anti-TNF therapy is associated with an increased risk of serious infections in patients with rheumatoid arthritis especially in the first 6 months of treatment: updated results from the British Society for Rheumatology Biologics Register with special emphasis on risks in the elderly. Rheumatology (2011) 50:124-31. doi:10.1093/rheumatology/keq242

16. van Crevel R, Karyadi E, Preyers F, Leenders M, Kullberg BJ, Nelwan H, et al. Increased production of interleukin 4 by CD4+ and CD8+ T cells from patients with tuberculosis is related to the presence of pulmonary cavities. J Infect Dis (2000) 181:1194-7. doi:10.1086/315325

17. Morosini M, Meloni F, Marone Bianco A, Paschetto E, Uccelli M, Pozzi E, et al. The assessment of IFN-gamma and its regulatory cytokines in the plasma and bronchoalveolar lavage fluid of patients with active pulmonary tuberculosis. Int J Tuberc Lung Dis (2003) 7:994-1000.

18. Ordway DJ, Costa L, Martins M, Silveira H, Amaral L, Arroz MJ, et al. Increased interleukin-4 production by CD8 and gammadelta T cells in health-care workers is associated with the subsequent development of active tuberculosis. J Infect Dis (2004) 190:756-66. doi:10.1086/422532

19. Harari A, Vallelian F, Meylan PR, Pantaleo G. Functional heterogeneity of memory CD4 $\mathrm{T}$ cell responses in different conditions of antigen exposure and persistence. J Immunol (2005) 174:1037-45.

20. Beveridge NE, Price DA, Casazza JP, Pathan AA, Sander CR, Asher TE, et al. Immunisation with BCG and recombinant MVA85A induces long-lasting, polyfunctional Mycobacterium tuberculosis-specific CD4+ memory T lymphocyte populations. Eur J Immunol (2007) 37:3089-100. doi:10.1002/eji.200737504

21. Day CL, Mkhwanazi N, Reddy S, Mncube Z, van der Stok M, Klenerman P, et al. Detection of polyfunctional Mycobacterium tuberculosis-specific T cells and association with viral load in HIV-1-infected persons. J Infect Dis (2008) 197:990-9. doi:10.1086/529048

22. Sutherland JS, Adetifa IM, Hill PC, Adegbola RA, Ota MOC. Pattern and diversity of cytokine production differentiates between Mycobacterium tuberculosis infection and disease. Eur J Immunol (2009) 39:723-9. doi:10.1002/eji.200838693

23. Scriba TJ, Tameris M, Mansoor N, Smit E, Van Der Merwe L, Isaacs F, et al. Modified vaccinia Ankara-expressing Ag85A, a novel tuberculosis vaccine, is safe in adolescents and children, and induces polyfunctional CD4+ T cells. Eur J Immunol (2010) 40:279-90. doi:10.1002/eji.200939754

24. Acosta-Rodriguez EV, Rivino L, Geginat J, Jarrossay D, Gattorno M, Lanzavecchia A, et al. Surface phenotype and antigenic specificity of human interleukin 17-producing T helper memory cells. Nat Immunol (2007) 8:639-46. doi:10.1038/ni1467

25. Khader SA, Bell GK, Pearl JE, Fountain JJ, Rangel-Moreno J, Cilley GE, et al. IL-23 and IL-17 in the establishment of protective pulmonary CD4+ T cell responses after vaccination and during Mycobacterium tuberculosis challenge. Nat Immunol (2007) 8:369-77. doi:10.1038/ni1449

26. Scriba TJ, Kalsdorf B, Abrahams D-A, Isaacs F, Hofmeister J, Black G, et al. Distinct, specific IL-17- and IL-22-producing CD4+ T cell subsets contribute to the human anti-mycobacterial immune response. J Immunol (2008) 180: 1962-70.

27. Basile JI, Geffner LJ, Romero MM, Balboa L, Sabio YGC, Ritacco V, et al. Outbreaks of Mycobacterium tuberculosis MDR strains induce high IL-17 T-cell 
response in patients with MDR tuberculosis that is closely associated with high antigen load. J Infect Dis (2011) 204:1054-64. doi:10.1093/infdis/jir460

28. Jurado JO, Pasquinelli V, Alvarez IB, Peña D, Rovetta AI, Tateosian NL, et al. IL17 and IFN- $\gamma$ expression in lymphocytes from patients with active tuberculosis correlates with the severity of the disease. J Leukoc Biol (2012) 91:991-1002. doi:10.1189/jlb.1211619

29. Redford PS, Murray PJ, O'Garra A. The role of IL-10 in immune regulation during M. tuberculosis infection. Mucosal Immunol (2011) 4:261-70. doi:10.1038/mi.2011.7

30. Verbon A, Juffermans N, Van Deventer SJ, Speelman P, Van Deutekom H, Van Der Poll T. Serum concentrations of cytokines in patients with active tuberculosis (TB) and after treatment. Clin Exp Immunol (1999) 115:110-3. doi:10.1046/j.1365-2249.1999.00783.x

31. Sette A, Sidney J. Nine major HLA class I supertypes account for the vast preponderance of HLA-A and -B polymorphism. Immunogenetics (1999) 50:201-12. doi:10.1007/s002510050594

32. Greenbaum J, Sidney J, Chung J, Brander C, Peters B, Sette A. Functional classification of class II human leukocyte antigen (HLA) molecules reveals seven different supertypes and a surprising degree of repertoire sharing across supertypes. Immunogenetics (2011) 63:325-35. doi:10.1007/s00251-011-0513-0

33. McKinney DM, Southwood S, Hinz D, Oseroff C, Arlehamn CS, Schulten V, et al. A strategy to determine HLA class II restriction broadly covering the DR, DP, and DQ allelic variants most commonly expressed in the general population. Immunogenetics (2013) 65:357-70. doi:10.1007/s00251-013-0684-y

34. Alexander J, Sidney J, Southwood S, Ruppert J, Oseroff C, Maewal A, et al. Development of high potency universal DR-restricted helper epitopes by modification of high affinity DR-blocking peptides. Immunity (1994) 1:751-61. doi:10.1016/S1074-7613(94)80017-0

35. Southwood S, Sidney J, Kondo A, Del Guercio M-F, Appella E, Hoffman S, et al. Several common HLA-DR types share largely overlapping peptide binding repertoires. J Immunol (1998) 160:3363-73.

36. O’Sullivan D, Arrhenius T, Sidney J, Del Guercio MF, Albertson M, Wall M, et al. On the interaction of promiscuous antigenic peptides with different DR alleles. Identification of common structural motifs. J Immunol (1991) 147:2663-9.

37. Castelli FA, Buhot C, Sanson A, Zarour H, Pouvelle-Moratille S, Nonn C, et al. HLA-DP4, the most frequent HLA II molecule, defines a new supertype of peptide-binding specificity. J Immunol (2002) 169:6928-34.

38. Berretta F, Butler RH, Diaz G, Sanarico N, Arroyo J, Fraziano M, et al. Detailed analysis of the effects of Glu/Lys beta69 human leukocyte antigen-DP polymorphism on peptide-binding specificity. Tissue Antigens (2003) 62:459-71. doi:10.1046/j.1399-0039.2003.00131.x

39. Sidney J, Steen A, Moore C, Ngo S, Chung J, Peters B, et al. Five HLA-DP molecules frequently expressed in the worldwide human population share a common HLA supertypic binding specificity. J Immunol (2010) 184:2492-503. doi:10.4049/jimmunol.0903655

40. Sidney J, Del Guercio MF, Southwood S, Sette A. The HLA molecules $\mathrm{DQA}^{\star}{ }^{\star} 0501 / \mathrm{B} 1^{\star} 0201$ and $\mathrm{DQA} 1^{\star} 0301 / \mathrm{B} 1^{\star} 0302$ share an extensive overlap in peptide binding specificity. J Immunol (2002) 169:5098-108.

41. Sidney J, Steen A, Moore C, Ngo S, Chung J, Peters B, et al. Divergent motifs but overlapping binding repertoires of six HLA-DQ molecules frequently expressed in the worldwide human population. J Immunol (2010) 185:4189-98. doi:10.4049/jimmunol.1001006

42. Chelvanayagam G. A roadmap for HLA-DR peptide binding specificities. Hum Immunol (1997) 58:61-9.

43. Ou D, Mitchell LA, Tingle AJ. A new categorization of HLA DR alleles on a functional basis. Hum Immunol (1998) 59:665-76. doi:10.1016/S0198-8859(98) 00067-6

44. Doytchinova IA, Flower DR. In silico identification of supertypes for class II MHCs. J Immunol (2005) 174:7085-95.

45. Nielsen M, Lund O, Buus S, Lundegaard C. MHC class II epitope predictive algorithms. Immunology (2010) 130:319-28. doi:10.1111/j.1365-2567.2010.03268.x

46. Lamonaca V, Missale G, Urbani S, Pilli M, Boni C, Mori C, et al. Conserved hepatitis $\mathrm{C}$ virus sequences are highly immunogenic for CD4(+) $\mathrm{T}$ cells: implications for vaccine development. Hepatology (1999) 30:1088-98. doi: $10.1002 /$ hep. 510300435

47. Doolan DL, Southwood S, Chesnut R, Appella E, Gomez E, Richards A, et al. HLA-DR-promiscuous $\mathrm{T}$ cell epitopes from Plasmodium falciparum preerythrocytic-stage antigens restricted by multiple HLA class II alleles. J Immunol (2000) 165:1123-37.
48. Wilson CC, Palmer B, Southwood S, Sidney J, Higashimoto Y, Appella E, et al. Identification and antigenicity of broadly cross-reactive and conserved human immunodeficiency virus type 1-derived helper T-lymphocyte epitopes. J Virol (2001) 75:4195-207. doi:10.1128/JVI.75.9.4195-4207.2001

49. Tangri S, Mothe BR, Eisenbraun J, Sidney J, Southwood S, Briggs K, et al. Rationally engineered therapeutic proteins with reduced immunogenicity. Jimmunol (2005) 174:3187-96.

50. Lindestam Arlehamn CS, Sidney J, Henderson R, Greenbaum JA, James EA, Moutaftsi M, et al. Dissecting mechanisms of immunodominance to the common tuberculosis antigens ESAT-6, CFP10, Rv2031c (hspX), Rv2654c (TB7.7), and Rv1038c (EsxJ). J Immunol (2012) 188:5020-31. doi:10.4049/jimmunol. 1103556

51. Assarsson E, Bui H-H, Sidney J, Zhang Q, Glenn J, Oseroff C, et al. Immunomic analysis of the repertoire of T-cell specificities for influenza A virus in humans. J Virol (2008) 82:12241-51. doi:10.1128/JVI.01563-08

52. Oseroff C, Sidney J, Kotturi MF, Kolla R, Alam R, Broide DH, et al. Molecular determinants of $\mathrm{T}$ cell epitope recognition to the common Timothy grass allergen. J Immunol (2010) 185:943-55. doi:10.4049/jimmunol.1000405

53. Oseroff C, Sidney J, Tripple V, Grey H, Wood R, Broide DH, et al. Analysis of $\mathrm{T}$ cell responses to the major allergens from German cockroach: epitope specificity and relationship to IgE production. J Immunol (2012) 189:679-88. doi:10.4049/jimmunol.1200694

54. Oseroff C, Sidney J, Vita R, Tripple V, Mckinney DM, Southwood S, et al. T cell responses to known allergen proteins are differently polarized and account for a variable fraction of total response to allergen extracts. J Immunol (2012) 189:1800-11. doi:10.4049/jimmunol.1200850

55. Wang P, Sidney J, Kim Y, Sette A, Lund O, Nielsen M, et al. Peptide binding predictions for HLA DR, DP and DQ molecules. BMC Bioinformatics (2010) 11:568. doi:10.1186/1471-2105-11-568

56. Cole S, Brosch R, Parkhill J, Garnier T, Churcher C, Harris D, et al. Deciphering the biology of Mycobacterium tuberculosis from the complete genome sequence. Nature (1998) 393:537-544. doi:10.1038/31159

57. Lindestam Arlehamn CS, Gerasimova A, Mele F, Henderson R, Swann J, Greenbaum JA, et al. Memory $\mathrm{T}$ cells in latent Mycobacterium tuberculosis infection are directed against three antigenic islands and largely contained in a CXCR3+CCR6+ Th1 subset. PLoS Pathog (2013) 9:e1003130. doi:10.1371/ journal.ppat.1003130

58. Gosselin A, Monteiro P, Chomont N, Diaz-Griffero F, Said EA, Fonseca $\mathrm{S}$, et al. Peripheral blood CCR4+CCR6+ and CXCR3+CCR6+CD4+ T cells are highly permissive to HIV-1 infection. J Immunol (2010) 184:1604-16. doi:10.4049/jimmunol.0903058

59. Tameris MD, Hatherill M, Landry BS, Scriba TJ, Snowden MA, Lockhart S, et al. Safety and efficacy of MVA85A, a new tuberculosis vaccine, in infants previously vaccinated with BCG: a randomised, placebo-controlled phase $2 \mathrm{~b}$ trial. Lancet (2013) 381:1021-8. doi:10.1016/S0140-6736(13)60177-4

60. Lew JM, Kapopoulou A, Jones LM, Cole ST. TubercuList - 10 years after. Tuberculosis (2011) 91:1-7. doi:10.1016/j.tube.2010.09.008

61. Andersen P. The T cell response to secreted antigens of Mycobacterium tuberculosis. Immunobiology (1994) 191:537-47. doi:10.1016/S0171-2985(11)80460-2

62. Boesen H, Jensen B, Wilcke T, Andersen P. Human T-cell responses to secreted antigen fractions of Mycobacterium tuberculosis. Infect Immun (1995) 63:1491-7.

63. Blythe M, Zhang Q, Vaughan K, De Castro R, Salimi N, Bui H-H, et al. An analysis of the epitope knowledge related to mycobacteria. Immunome Res (2007) 3:10. doi:10.1186/1745-7580-3-10

64. Gey Van Pittius N, Gamieldien J, Hide W, Brown G, Siezen R, Beyers A. The ESAT-6 gene cluster of Mycobacterium tuberculosis and other high G+C Grampositive bacteria. Genome Biol (2001) 2:research0044.0041-research0044.0018. doi:10.1186/gb-2001-2-10-research0044

65. Geiger R, Duhen T, Lanzavecchia A, Sallusto F. Human naive and memory $\mathrm{CD} 4+\mathrm{T}$ cell repertoires specific for naturally processed antigens analyzed using libraries of amplified T cells. J Exp Med (2009) 206:1525-34. doi:10.1084/jem.20090504

66. Barnes E, Ward SM, Kasprowicz VO, Dusheiko G, Klenerman P, Lucas M. Ultrasensitive class I tetramer analysis reveals previously undetectable populations of antiviral CD8+ T cells. Eur J Immunol (2004) 34:1570-7. doi:10.1002/eji. 200424898

67. Zielinski CE, Corti D, Mele F, Pinto D, Lanzavecchia A, Sallusto F. Dissecting the human immunologic memory for pathogens. Immunol Rev (2011) 240:40-51. doi:10.1111/j.1600-065X.2010.01000.x 
68. Sidney J, Southwood S, Moore C, Oseroff C, Pinilla C, Grey HM, et al. Measurement of $\mathrm{MHC} /$ peptide interactions by gel filtration or monoclonal antibody capture. Curr Protoc Immunol (2013) Chapter 18:Unit18.13. doi:10.1002/ 0471142735.im1803s 100

69. Young DB, Gideon HP, Wilkinson RJ. Eliminating latent tuberculosis. Trends Microbiol (2009) 17:183-8. doi:10.1016/j.tim.2009.02.005

70. Wilkinson RJ, De Smet KA, Haslov K, Pasvol G, Singh M, Svarcova I, et al. Human $\mathrm{T}$ - and B-cell reactivity to the $16 \mathrm{kDa}$ alpha-crystallin protein of Mycobacterium tuberculosis. Scand J Immunol (1998) 48:403-9. doi:10.1046/j.1365-3083.1998. 00420.x

71. Leyten EMS, Lin MY, Franken KLMC, Friggen AH, Prins C, Van Meijgaarden $\mathrm{KE}$, et al. Human T-cell responses to 25 novel antigens encoded by genes of the dormancy regulon of Mycobacterium tuberculosis. Microbes Infect (2006) 8:2052-60. doi:10.1016/j.micinf.2006.03.018

72. Wayne LG, Sohaskey CD. Nonreplicating persistence of Mycobacterium tuberculosis. Annu Rev Microbiol (2001) 55:139-63. doi:10.1146/annurev.micro.55.1. 139

73. Sherman DR, Voskuil M, Schnappinger D, Liao R, Harrell MI, Schoolnik GK. Regulation of the Mycobacterium tuberculosis hypoxic response gene encoding alpha-crystallin. Proc Natl Acad Sci U S A (2001) 98:7534-9. doi:10.1073/pnas. 121172498

74. Roberts DM, Liao RP, Wisedchaisri G, Hol WG, Sherman DR. Two sensor kinases contribute to the hypoxic response of Mycobacterium tuberculosis. J Biol Chem (2004) 279:23082-7. doi:10.1074/jbc.M401230200

75. Demissie A, Leyten EMS, Abebe M, Wassie L, Aseffa A, Abate G, et al. Recognition of stage-specific mycobacterial antigens differentiates between acute and latent infections with Mycobacterium tuberculosis. Clin Vaccine Immunol (2006) 13:179-86. doi:10.1128/CVI.13.2.179-186.2006

76. Geluk A, Lin MY, Van Meijgaarden KE, Leyten EMS, Franken KLMC, Ottenhoff THM, et al. T-cell recognition of the HspX protein of Mycobacterium tuberculosis correlates with latent $M$. tuberculosis infection but not with $M$. bovis BCG vaccination. Infect Immun (2007) 75:2914-21. doi:10.1128/IAI.01990-06

77. Roupie V, Romano M, Zhang L, Korf H, Lin MY, Franken KLMC, et al. Immunogenicity of eight dormancy regulon-encoded proteins of Mycobacterium tuberculosis in DNA-vaccinated and tuberculosis-infected mice. Infect Immun (2007) 75:941-9. doi:10.1128/IAI.01137-06

78. Schuck SD, Mueller H, Kunitz F, Neher A, Hoffmann H, Franken KLCM, et al. Identification of T-cell antigens specific for latent Mycobacterium Tuberculosis infection. PLoS One (2009) 4:e5590. doi:10.1371/journal.pone.0005590

79. Commandeur S, Van Meijgaarden KE, Lin MY, Franken KLMC, Friggen AH, Drijfhout JW, et al. Identification of human T-cell responses to Mycobacterium tuberculosis resuscitation promoting factors in long-term latently infected individuals. Clin Vaccine Immunol (2011) 18:676-83. doi:10.1128/CVI.00492-10

80. Kell DB, Young M. Bacterial dormancy and culturability: the role of autocrine growth factors. Curr Opin Microbiol (2000) 3:238-43. doi:10.1016/S13695274(00)00082-5

81. Colditz GA, Berkey CS, Mosteller F, Brewer TF, Wilson ME, Burdick E, et al. The efficacy of bacillus Calmette-Guerin vaccination of newborns and infants in the prevention of tuberculosis: meta-analyses of the published literature. Pediatrics (1995) 96:29-35.
82. Fine PE. Variation in protection by BCG: implications of and for heterologous immunity. Lancet (1995) 346:1339-45. doi:10.1016/S0140-6736(95)92348-9

83. Trunz BB, Fine P, Dye C. Effect of BCG vaccination on childhood tuberculous meningitis and miliary tuberculosis worldwide: a meta-analysis and assessment of cost-effectiveness. Lancet (2006) 367:1173-80. doi:10.1016/S0140-6736(06) 68507-3

84. McShane H, Pathan AA, Sander CR, Keating SM, Gilbert SC, Huygen K, et al. Recombinant modified vaccinia virus Ankara expressing antigen $85 \mathrm{~A}$ boosts BCG-primed and naturally acquired antimycobacterial immunity in humans. Nat Med (2004) 10:1240-4. doi:10.1038/nm1128

85. Scriba TJ, Tameris M, Mansoor N, Smit E, Van Der Merwe L, Mauff K, et al. Dose-finding study of the novel tuberculosis vaccine, MVA85A, in healthy BCGvaccinated infants. J Infect Dis (2011) 203:1832-43. doi:10.1093/infdis/jir195

86. D’Souza S, Rosseels V, Romano M, Tanghe A, Denis O, Jurion F, et al. Mapping of murine Th1 helper T-cell epitopes of mycolyl transferases Ag85A, Ag85B, and Ag85C from Mycobacterium tuberculosis. Infect Immun (2003) 71:483-93. doi:10.1128/IAI.71.1.483-493.2003

87. Ravn P, Boesen H, Pedersen BK, Andersen P. Human T cell responses induced by vaccination with Mycobacterium bovis bacillus Calmette-Guerin. J Immunol (1997) 158:1949-55.

88. Kagina BM, Abel B, Scriba TJ, Hughes EJ, Keyser A, Soares A, et al. Specific T cell frequency and cytokine expression profile do not correlate with protection against tuberculosis after bacillus Calmette-Guerin vaccination of newborns. Am J Respir Crit Care Med (2010) 182:1073-9. doi:10.1164/rccm.201003-0334OC

89. Hanekom WA. The immune response to BCG vaccination of newborns. Ann N Y Acad Sci (2005) 1062:69-78. doi:10.1196/annals.1358.010

90. Orme IM. The Achilles heel of BCG. Tuberculosis (2010) 90:329-32. doi:10.1016/ j.tube.2010.06.002

91. Abebe F. Is interferon-gamma the right marker for bacille Calmette-Guérininduced immune protection? The missing link in our understanding of tuberculosis immunology. Clin Exp Immunol (2012) 169:213-9. doi:10.1111/j.13652249.2012.04614.x

Conflict of Interest Statement: The authors declare that the research was conducted in the absence of any commercial or financial relationships that could be construed as a potential conflict of interest.

Received: 30 January 2014; paper pending published: 24 February 2014; accepted: 11 March 2014; published online: 24 March 2014.

Citation: Lindestam Arlehamn CS and Sette A (2014) Definition of CD4 immunosignatures associated with MTB. Front. Immunol. 5:124. doi: 10.3389/fimmu.2014.00124 This article was submitted to Microbial Immunology, a section of the journal Frontiers in Immunology.

Copyright (C) 2014 Lindestam Arlehamn and Sette. This is an open-access article distributed under the terms of the Creative Commons Attribution License (CC BY). The use, distribution or reproduction in other forums is permitted, provided the original author(s) or licensor are credited and that the original publication in this journal is cited, in accordance with accepted academic practice. No use, distribution or reproduction is permitted which does not comply with these terms. 